\title{
POR UM METADOGMATISMO NO ENSINO JURÍDICO: O PENSAMENTO JURÍDICO CRÍTICO COMO CORTE EPISTEMOLÓGICO
}

\section{FOR A METADOGMATISM IN THE JURÍDICAL EDUCATION: THE CRITICAL JURIDICAL THINKING AS A EPISTEMOLOGICAL BREAK}

\author{
GUILHERME CAVICCHIOLI UCHIMURA \\ Acadêmico do Curso de Direito da Universidade Estadual de Londrina \\ guilherme.uchimura@hotmail.com
}

\section{RESUMO}

0 presente trabalho analisa a crise do ensino jurídico atual com base no pressuposto de que o homem deve reivindicar o máximo de liberdade possível para si. Levando em consideração elementos como a função política do Direito e a mercadorização do ensino que se agrava cada vez mais, estabelece uma abordagem desse cenário sob a perspectiva da teoria da crise da modernidade de Boaventura de S. Santos e da teoria dos obstáculos epistemológicos de Gaston Bachelard. Identifica o pensamento jurídico crítico como corte epistemológico necessário para a ruptura com a castração positivista e o pensamento dogmático dominante, situando o conhecimento de forma histórica, não linear e envolvido pela dialética social. Conclui que a emersão do pensamento metadogmático no ensino do direito é o primeiro passo para a construção de um novo saber jurídico, fundado em uma práxis emancipatória e compromissada com a libertação humana, assim como é defendida a perspectiva jurídica na obra de Roberto Lyra Filho a que se faz constante referência.

Palavras-chave: Crise do ensino jurídico; Práxis jurídica emancipatória; Teoria dos obstáculos epistemológicos.

\begin{abstract}
This work analyses the actual juridical education crises based on the assumption that man should require the most of freedom as possible for himself. Taking in consideration elements such as the political function of Law and the education commodification that increasingly worsens, it establishes an approaching of this context under the modernity crises theory from Boaventura de S. Santos and under the epistemological obstacle theory from Bachelard. Identifies the critical juridical thinking as an epistemological break required for the rupture with the positivist castration and the prevailing dogmatic thinking, situating knowledge in historical, nonlinear and involved by the social dialectical form. It concludes that the emersion of the metadogmatic thinking is the first step for the construction of a new juridical knowledge, founded in an emancipatory praxis and compromised with the human freedom process, as well as the juridical perspective is defended in the Roberto Lyra Filho's work to which references are made constantly.
\end{abstract}

Keywords: Epistemological obstacle theory; Juridical education crises. Juridical emancipatory praxis.

\section{SUMÁRIO}

INTRODUÇÃO; 1 POR QUE ESTUDAR DIREITO HOJE?; 2 PENSAMENTO JURÍDICO CRÍTICO COMO CORTE EPISTEMOLÓGICO; 2.1 CRISE DA MODERNIDADE; 2.2 TEORIA DOS OBSTÁCULOS EPISTEMOLÓGICOS; 2.3 FUNDAMENTOS DO PENSAMENTO JURÍDICO CRÍTICO; 2.4 POR UM METADOGMATISMO NO ENSINO JURÍDICO; 3 DIREITO COMO PROCESSO DE LIBERTAÇÃO; CONCLUSÃO; REFERÊNCIAS. 


\section{INTRODUÇÃO}

"Liberdade - essa palavra /Que o sonho humano alimenta: /Que não há ninguém que explique, /E ninguém que não entenda"1. A luta pela liberdade, ainda que em sua intangibilidade e volatilidade conceitual, como expressam os versos de Cecília, é o que marca fundamentalmente a motivação deste trabalho e de toda sua linha de pesquisa.

$\mathrm{Na}$ área do direito, como ensina Óscar Correas² ${ }^{2}$ devemos ficar de sobreaviso contra toda forma jurídica; ser vigilantes e desconfiados com as normas, e não apenas resignados ao aceitálas, reivindicando sempre o máximo de liberdade possível nos meandros normativos. Isso leva ao necessário comprometimento com uma práxis crítica, que questiona o direito a todo instante e cria estratégias para reconstruí-lo na direção de torná-lo cada vez mais, ao invés de um instrumento de dominação social, um caminho para a libertação humana.

Sem perspectiva crítica, o direito acaba se tornando um corredor mais e mais estreito, em que as paredes do dogmatismo vão se convergindo entre si, sufocando os operadores em um afã hermeticamente individualista, e esmagando os anseios populares sem sequer conseguir enxergá-los. Com isso, começa a ficar clara a urgência e a necessidade de se buscar formulações alternativas à dimensão hegemônica do Direito, de o jurista comprometer-se com uma práxis crítica, libertadora e realmente envolvida com a realidade social.

O dogmatismo, depositado na mente dos estudantes de Direito, constitui verdadeiro obstáculo epistemológico às ciências jurídicas do ponto de vista social. Ao revés desse conhecimento fechado e estático, a cultura científica deve estar em estado de mobilização permanente, consciente da própria dialeticidade, resultando em um saber aberto e dinâmico.

Nessa direção, foi aparecendo nas últimas décadas o pensamento jurídico crítico. Minha tese é que esse novo conjunto de conhecimentos pode ser visto como uma maneira romper com o saber jurídico sacramentado, isto é, um corte epistemológico no sentido bachelardiano.

Apresento este artigo, principalmente, como um apelo. 0 dogmatismo como pensamento dominante no ensino jurídico nacional constitui um poderoso instrumental classista

\footnotetext{
1 MEIRELES, Cecília. Romance XXIV ou Da Bandeira da Inconfidência. In: Romanceiro da inconfidência. 4. ed. Rio de Janeiro: Civilização Brasiliense, 1984. p.75.

${ }^{2}$ CORREAS, Oscar. Crítica da ideologia jurídica: ensaio sócio-semiológico. Porto Alegre: Sérgio Antônio Fabris, 1995a, p.60.
} 
a serviço da legitimação dos processos de hegemonia e dominação estabelecidos. Na luta pela maior liberdade possível ao homem, fica claro que já passou a hora de superá-lo.

No primeiro capítulo, farei uma breve análise da crise do ensino jurídico pela qual passamos, identificando a hegemonia do pensamento dogmático como principal responsável pela acriticidade presente nos cursos de Direito. No segundo capítulo, apresentarei pesquisa bibliográfica na área da sociologia jurídica e da epistemologia para demonstrar que, no contexto atual, a superação do dogmatismo é necessária para se construir uma práxis jurídica emancipatória. Na terceira etapa do trabalho, demonstrarei que superar o dogmatismo no ensino jurídico é o primeiro passo para a construção de um viés emancipatório no saber e na práxis do Direito.

\section{POR QUE ESTUDAR DIREITO HOJE?}

Por que estudar direito, hoje? é o título de um artigo de Lyra Filho publicado em 1988 na obra Direito Achado na Rua ${ }^{3}$. Na época, já se falava em uma crise no saber jurídico e na necessidade de se rever a sistemática do ensino nos cursos de Direito.

Vinte e cinco anos depois, a crise parece somente ter se agravado. Hoje, os problemas remetem às perspectivas com que o aluno entra na faculdade, muitos pensando apenas em obter o título da graduação para ingressar em concursos públicos, e outros bitolados em passar no exame da ordem, ambos preocupados apenas em descobrir qual o melhor caminho para ganhar mais dinheiro.

Isso torna o curso de Direito, na prática, um curso de formação técnica. Parece óbvio que, em geral, falta no âmbito dos cursos de Direito a valorização da criticidade e do envolvimento com a realidade social.

Soma-se a isso que o sistema da lógica do lucro parece ter logo se apropriado das preocupações dos estudantes e profissionais. Quando se fala em mercadorização do ensino, é fácil perceber a existência de uma forte indústria que converte os anseios dos estudantes de Direito em acumulação de capital. É só olhar em volta para perceber a forma mercantil que o saber jurídico assume: faculdades de Direito se espalhando aos montes, milhares de manuais publicados diariamente, megacursinhos preparatórios jorrando rios de dinheiro aos sócios, sites

\footnotetext{
${ }^{3}$ LYRA FILHO, Roberto. Por que estudar direito, hoje? In: SOUSA JUNIOR, Geraldo de Sousa (Org.). 0 direito achado na rua: curso de extensão universitária à distância. Brasília: Universidade de Brasília, 1988.
} 
voltados à classe dos "concurseiros" e a até mesmo a própria forma da realização dos concursos públicos...

Esse "Direito junk food" se prolifera cada vez mais, e cada vez mais se impõe a naturalidade de consumi-lo para aqueles que querem "se dar bem na vida" se formando em Direito.

Essa crise é, inclusive, reconhecida de forma oficial. Basta ver que, em março de 2013, o Ministério da Educação e a Ordem dos Advogados do Brasil firmaram um acordo visando promover estudos para a reformulação da política regulatória do ensino jurídico ${ }^{4}$.

0 ponto que nos interessa nesse panorama é que, por trás dessa crise, reside uma visão estritamente dogmática do Direito imperando de forma dominante no ensino jurídico nacional, tornando o saber e a práxis do Direito algo predominantemente tecnicista e mecanicista.

Hoje, no ensino jurídico nacional, de forma hegemônica, a acriticidade leva ao apadrinhamento de uma visão legalista que favorece a classe dominante ${ }^{5}$. Desde cedo, ensina-se a acreditar nas ficções jurídicas como se fossem a única verdade: o Direito torna-se uma constante novela em que, de forma surrealista, os seus atores interpretam e acreditam no fictício roteiro deôntico contado pelas leis.

Dessa forma, o Direito, inserido na totalidade social, não passaria de um instrumento de dominação e hegemonia nas mãos dos poderosos; e isso tornaria a nós, os seus operadores, meros soldados do capital e defensores da opressão.

Lutando contra os absurdos dessa práxis alienada, a militância pela desmitificação dos postulados positivistas na área jurídica teve recentemente Luis Alberto Warat como grande expoente no Brasil. Em sua obra, o Direito, visto como elemento que cumpre função análoga ao "superego" da psicanálise freudiana, é desnudado como instrumento de poder:

Existe um certo consenso nas reflexões em torno das práticas interpretativas do Direito. Poucas ousadias e muitas fantasias perfeitas recobrem as teorias sobre a interpretação da lei. Métodos ilusórios, enobrecidas crenças, desapercebidos silêncios envolvem as práticas interpretativas dos juristas de ofício. Teorias e práticas encarregadas de garantir a institucionalização da produção judicial da normatividade e seus efeitos de poder na comunidade. Práticas, mitos e teorias refinadas que se ligam estreitamente aos processos de produção heterônoma da ordem simbólica da sociedade. Usos complacentes da lei que guardam, como em cofres de sete chaves, os princípios de controle da produção dos discursos

\footnotetext{
${ }^{4}$ MINISTÉRIO DA EDUCAÇÃO. MEC e OAB assinam acordo para aprimorar cursos de direito. Disponível em: <http://portal.mec.gov.br/index.php?option=com_content\&view=articleধtid=18533>. Acesso em: 31 ago 2013.

${ }^{5}$ PAULON, Carlos Artur. Direito alternativo do trabalho. São Paulo: LTr, 1984. p.22.
} 
jurídicos. Uma discursividade enganosamente cristalina que escamoteia, em nome da verdade, da segurança e da justiça, a presença subterrânea de uma "tecnologia da opressão" e de uma microfísica conflitiva de ocultamento que vão configurando as relações de poder inscritas no discurso da lei. ${ }^{6}$

Então, a pergunta. Por que estudar Direito hoje?

0 ponto que defendo é que o dogmatismo já deveria estar mais do superado no contexto atual do saber humano. É necessária, hoje, uma compreensão do fenômeno jurídico a partir dos diversos sistemas de conhecimento desenvolvidos no decorrer dos últimos séculos, tais quais a psicanálise, a linguística, a antropologia, a dialética e o marxismo.

Tanto no aspecto da interpretação das normas quanto na percepção do fenômeno jurídico na totalidade social, o dogmatismo apresenta-se já cansado, resistindo muito mais por comodismo mútuo entre professores e alunos do que por convicção filosófica destes no positivismo. Como defende Roberto Lyra Filho:

[...] assim como a triunfante visão da pluralidade dos ordenamentos jurídicos fez explodir a concepção do ordenamento único, hermético e estatal, a teoria e prática da interpretação, considerando, cientificamente, este suposto ordenamento único, em suposta coerência intra-sistemática, fez implodir o esquema tradicional das fontes e da hermenêutica. ${ }^{7}$

Nesse sentido, estudar o Direito hoje implica, de uma forma ou de outra, fazer uma opção política por engajar-se ou não: como lembra Lyra Filho, escolher não fazer política já constitui uma maneira de fazer política. Em suas palavras,

Direito é desenganadamente política, e a questão não é ser político ou não sê-lo, pois não sê-lo é um disfarce que adota a opção política conservadora - isto é, não querer que o estudante ou professor "façam política", porque esperam que eles se acomodem docilmente à política oficial, que já traçou a função e a maneira de exercê-la. ${ }^{8}$

Pois bem. Nesse contexto, a proposta deste trabalho é, reconhecendo a crise do sistema de ensino jurídico, pesquisar como podemos superá-la em uma direção construtiva e estabelecendo o Direito, tanto na teoria quanto na prática, como um processo de libertação.

Essa será a tarefa dos próximos capítulos.

\footnotetext{
6 WARAT, Luis Alberto. Introdução geral ao direito. v.1. Interpretação da lei: temas para uma reformulação. Porto Alegre: Sergio Antonio Fabris, 1994. p.19.

${ }^{7}$ LYRA FILHO, 1988, ob.cit., p.26.

${ }^{8}$ Ibidem, p. 30 .
} 


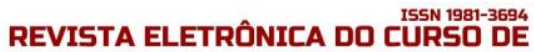

\section{PENSAMENTO JURÍDICO CRÍTICO COMO CORTE EPISTEMOLÓGICO}

\subsection{Crise da Modernidade}

O sociólogo Boaventura de S. Santos sustenta que, na atualidade, chegou-se a um colapso da emancipação na regulação, assinalado como a falta de renovação da modernidade e, consequentemente, como a entrada no processo de crise final de seu paradigma 9 .

Vivemos, devido a isso, uma época de transição paradigmática, que o autor identifica como uma transição semicega e semi-invisível, entre a morte e a utopia ${ }^{10}$. Nela, o des-pensar as ciências sociais emerge como tarefa fundamental a todos nós ${ }^{11}$ : a teoria deve, além de desmitificar as estruturas da sociedade capitalista, transformar-se em um senso comum novo e emancipatório ${ }^{12}$.

Essa transição paradigmática, na verdade, já está em curso. Já se ouvem os passos da substituição do paradigma da modernidade ecoando pelos espaços sociais. Isso nos leva a um permanente conflito entre o paradigma dominante e o emergente. Assim, para tentar vislumbrar qualquer horizonte emancipatório possível, mais importante do que a "brilhante" racionalidade moderna, torna-se necessário desconstruir os nossos sistemas de explicação da realidade social e criar estruturas sociais novas e alternativas.

Dessa forma, é fundamental estabelecer uma forma de des-pensar o Direito. Em particular, isso significa questioná-lo a todo instante e criar estratégias para reconstruí-lo na direção de torná-lo cada vez mais, em vez de um instrumento de dominação social, um caminho para a libertação humana. No ramo jurídico, isso implica "abrir a cabeça” e aderir a ideários alternativos, metadogmáticos, formas críticas de pensar o Direito, como, por exemplo, o pluralismo jurídico, o Direito achado na rua, o Direito insurgente, o uso alternativo do Direito e a escola do Direito livre.

\footnotetext{
${ }^{9}$ WOLKMER, Antonio Carlos. Introdução ao pensamento jurídico crítico. 8. ed. São Paulo: Saraiva, 2012. ,p.87.

10 SANTOS, Boaventura de Sousa. Para um novo senso comum: a ciência e a política na transição paradigmática. v.1. A crítica da razão indolente: para um novo senso comum. 3. ed. São Paulo: Cortez, 2001. p.15.

11 Ibidem, p.166.

12 Ibidem, p.326-327.
} 


\subsection{Teoria dos Obstáculos Epistemológicos}

No contexto descrito no item anterior, foi aparecendo nas últimas décadas um conjunto de teorias alternativas, que o professor Wolkmer agrupou sob a denominação pensamento jurídico crítico.

Segundo a teoria dos obstáculos epistemológicos de Gaston Bachelard, as ciências avançam superando as crises de conhecimento que nelas se estabelecem e criando novos sistemas de explicação. A essas superações, o autor deu o nome de corte epistemológico, que aparece também como ruptura epistemológica e cesura epistemológica em algumas passagens de sua obra.

Com esses dois conceitos, obstáculo epistemológico e corte epistemológico, tem-se a noção de como a ciência se movimenta de forma histórica e não linear.

Com essa nova forma de conceber a epistemologia, Bachlelard elege como tarefa fundamental "colocar a cultura científica em estado de mobilização permanente, substituir o saber fechado e estático por um conhecimento aberto e dinâmico, dialetizar todas as variáveis experimentais, oferecer enfim à razão razões para evoluir". ${ }^{13}$

Nesses termos, reconhecendo-se a crise estabelecida no ensino jurídico nacional há décadas, a meu ver, o dogmatismo aparece como o obstáculo epistemológico que imobiliza o Direito, tanto na teoria quanto na prática. A minha tese é que o pensamento jurídico crítico seria o corte epistemológico que poderia romper com a estagnação positivista do Direito.

Acredito ser amplamente necessária uma ruptura com o saber sacramentado e engessado, em fase de implosão em sua própria incapacidade de engendrar progresso cognitivo. Com o pensamento crítico, superando a castração positivista, estabelece-se o compromisso de elevar o conjunto de conhecimentos a uma teorização prospectiva, não dissociada do contato com a realidade social, mas, ao revés, envolvida em sua permanente construção.

\subsection{Fundamentos do Pensamento Jurídico Crítico}

Primeiramente, tomando as formulações da Escola de Frankfurt ${ }^{14}$ de forma resumida, a ideia de teoria crítica está ligada à produção de discursos de transformação social e de

\footnotetext{
13 BACHELARD, Gaston. A formação do espírito científico: contribuição para uma psicanálise do conhecimento. Rio de Janeiro: Contraponto, 1996. p.24.

${ }^{14}$ Ver ADORNO, Theodor W.; HORKHEIMER, Max. Dialética do esclarecimento: fragmentos filosóficos. 2. ed. Rio de Janeiro: Jorge Zahar, 1985.
} 
emancipação. Trata-se do comprometimento do saber com a desmitificação e o esclarecimento, voltando-se à articulação de estratégias de ruptura com as formas de dominação ${ }^{15}$.

Boaventura S. Santos assinala que "a luta por objetivos emancipatórios é intrínseca à teoria crítica" e que, de certa forma, somos obrigados a buscar alternativas teoricamente fundadas a nossas interrogações e desassossegos ${ }^{16}$. Destaca ainda que, para a teoria crítica ser socialmente eficaz, ela deve transcender a esfera teórica. Não deve apenas desmitificar o senso comum das sociedades capitalistas, que "lubrifica e oculta as complexas constelações de poder de direito e de conhecimento", mas também tem o dever de "se transformar num senso comum novo e emancipatório" 17 .

Já a teoria crítica do Direito é entendida como uma forma de “questionar e romper com o normativo que está disciplinarmente ordenado e oficialmente consagrado (...)", culminando na "possibilidade de conceber e operacionalizar outras formas diferenciadas, não repressivas e emancipadoras, de prática jurídica" ${ }^{18}$. Trata-se de refletir e questionar a legalidade tradicional mitificada, constituída da linguagem normativa repressora e ritualizada, com o objetivo de "propiciar meios instrumentais para a conscientização e a emancipação dos sujeitos históricos na sua condição de dominados e excluído" 19 .

No mesmo sentido, a escola da Alemanha relaciona o Direito Crítico a uma "forma de emancipação humana, utopia concreta, práxis libertadora”. Com isso, “(...) penetra e desarticula as relações de poder social, econômico e político em vez de as legitimar"20.

Em uma perspectiva dialética, Roberto Lyra Filho defende que o Direito não é algo fixo e imóvel, mas “um processo de libertação permanente" ${ }^{21}$. Nesse sentido, a teoria jurídica crítica se coloca como uma linha de pensamento voltada à criação (poiesis) e ao desenvolvimento de formulações teóricas que, aplicadas à realidade, possam servir para libertar os oprimidos dentro dos movimentos da dialética social.

Vê-se que, nas últimas décadas, muito se produziu em um campo que Wolkmer denominou genericamente de pensamento jurídico crítico ${ }^{22}$ : trata-se de um arsenal conceitual

\footnotetext{
${ }^{15}$ WOLKMER, ob. cit., 2012, p.30-36.

${ }^{16}$ SANTOS, ob. cit., 2001, p.24-25.

17 Ibidem, p.326-327.

${ }^{18}$ WOLKMER, ob. cit., 2012 , p.44.

${ }^{19}$ Ibidem, p.116.

20 DE GIORGI citado WOLKMER, ob. cit., 2012, p.70.

${ }^{21}$ LYRA FILHO, Roberto. 0 que é Direito. 2. ed. São Paulo: Brasiliense, 1982b. p.115.

${ }^{22}$ WOLKMER, ob. cit., 2012.
} 
voltado a materializar a ruptura com a dominação dentro da área do Direito e, nela, possibilitar a emersão de projetos emancipatórios.

Em um universo que dá os primeiros passos com Elhrich ${ }^{23}$ e a teoria do Direito Vivo, e passa por Pachukanis, com a sua crítica marxista radical, hoje, no Brasil, muitos autores, com linhas diferentes, poderiam ainda ser citados neste grupo de "críticos", como Luis Fernanado Coelho, Miguel Pressburguer, Geraldo Sousa Junior, Alysson L. Mascaro, Juarez Cirino dos Santos, Carlos Arthur Paulon, Jorge Luis Souto Maior e tantos outros.

O conjunto de teorias críticas citado tem em comum a percepção da crise do dogmatismo e a formulação de teorias alternativas para se perceber o fenômeno jurídico. Dessa forma, o metadogmatismo, ou seja, a concepção de que o Direito não se reduz à sua face positivista, é o grande elemento unificador do pensamento jurídico crítico, tal qual o professor Wolkmer o compreende.

\subsection{Por um Metadogmatismo no Ensino Jurídico}

Em defesa de se identificar na crise do ensino jurídico o dogmatismo como obstáculo epistemológico e de se reconhecer a necessidade de superá-lo mediante um novo pensamento jurídico, cabe transcrever as palavras de Oscar Correas:

O máximo possível é uma resignada e vigilante aceitação da menor normatividade possível, e sob a condição de que seja consentida pelos dominados. Por isto a concepção que vê no Direito a organização da violência, que não permite ver nele nenhuma bondade intrínseca, que nos coloca de sobreaviso contra toda forma jurídica, que reivindica para o homem o máximo de liberdade possível, é uma convicção filosófica que marca irremediavelmente nossa concepção de direito. ${ }^{24}$

Assim como no trecho citado, o objetivo deste trabalho não é outro senão reivindicar ao homem o máximo de liberdade possível. Daí a necessidade de romper com o dogmatismo que mumifica, embalsama, envasilha, esteriliza, castra e torna hermético o Direito.

Como demonstrei anteriormente, a necessidade de superar esse modelo é imperiosa. Dar continuidade a ele só pode ser fruto de certo comodismo desenganado ou de uma estrita opção política reacionária.

${ }^{23}$ EHRLICH, Eügen. Fundamentos da sociologia do direito. Brasília: Universidade de Brasília, 1986.

${ }^{24}$ CORREAS, ob.cit., 1995, p.60. 
Os caminhos para lutar pela transformação do ensino jurídico hoje existem em diversos níveis. No nível institucional, por exemplo, trata-se de pressionar os órgãos oficiais pelo reconhecimento de diretrizes mais críticas nos planos de ensino. No plano da academia, reflete o engajamento, tanto docente quanto discente, em projetos alternativos de pesquisa e ensino, tendo como exemplo a NAIR (Nova Escola Jurídica Brasileira) de Lyra Filho e as Assessorias Jurídicas Universitárias Populares consolidadas em diversas universidades hoje.

A conscientização desse panorama e a desmitificação dos postulados positivistas do Direito constituem verdadeiros valores militantes para aqueles que acreditam na necessidade de um novo ensino jurídico.

O metadogmatismo é o primeiro passo para a construção de um Direito realmente emancipatório, visto como processo de libertação.

Aprofundarei nessa questão no capítulo seguinte.

\section{DIREITO COMO PROCESSO DE LIBERTAÇÃO}

Segundo muitos marxistas contemporâneos, a convergência da modernidade com o capitalismo teria feito o Direito emergir como uma categoria estritamente burguesa. Essa concepção reflete a tradição jusfilosófica fundada por Pachukanis de ligar o fenômeno jurídico tão-somente à reprodução da sociedade capitalista, retomando a metodologia mais radical do próprio Marx ${ }^{25}$ e identificando a existência do Direito apenas enquanto direito estatal burguês.

Já em Lyra Filho, que conta com a dialética do pluralismo jurídico para explicar o fenômeno do Direito, a coisa é diferente. Reconhece-se a insuficiência da concepção de estado monista adotado pelo projeto de modernidade burguês. Com isso, diferentemente de Pachukanis e de seus seguidores - que apenas levam em consideração a existência do direito estatal burguês -, Lyra Filho acaba englobando a coexistência de diversos sistemas normativos no fenômeno jurídico, que se realizam "não somente por imposições institucionais ou argumentos racionais, mas mediante as práticas internalizadas por uma extensa gama de novos atores sociais"26.

Em diversas passagens, ao defender o socialismo democrático, ele deixa claro que o Direito sempre continuará existindo dentro do processo histórico, mesmo após uma revolução comunista por exemplo. Não que o Direito possa ser considerado algo neutro, muito pelo

\footnotetext{
${ }^{25}$ Ver PACHUKANIS, Evgeni. A teoria geral do direito e o marxismo. Coimbra: Centelho, 1977.

${ }^{26}$ WOLKMER, 2012, ob.cit., p. 211.
} 
POR UM METADOGMATISMO NO ENSINO JURÍdICO: O Pensamento JuRídico Crítico Como CoRTe EPISTEMológico

contrário. Mas, segundo o pensamento lyriano, não se deve identificar todo o fenômeno jurídico com a forma burguesa, pois não se trata de uma coisa pronta e acabada: como disse mais de uma vez, "o Direito não é; ele vem a ser"27.

O Direito constitui-se em síntese inacabada como resultado das relações entre ordem e desordem dentro do processo histórico ${ }^{28}$, podendo representar, dentro de seu movimento dialético, um instrumental a serviço tanto da dominação quanto do rompimento com as estruturas hegemônicas do capital.

Nesse sentido, Lyra Filho se refere à luta de classes como parte do fenômeno jurídico:

A contradição entre a injustiça real das normas que apenas se dizer justas e a injustiça que nelas se encontra pertence ao processo, à dialética da realização do Direito, que é uma luta constante entre progressistas e reacionários, entre grupos e classes espoliadores e opressores. Esta luta faz parte do Direito, porque o Direito não é uma "coisa" fixa, parada, definitiva e eterna, mas um processo de libertação permanente.[...] Direito é processo, dentro do processo histórico: não é uma coisa feita, perfeita e acabada; é aquele vir-a-ser que se enriquece nos movimentos de libertação das classes e grupos ascendentes e que definha nas explorações e opressões que o contradizem, mas de cujas próprias contradições brotarão novas conquistas. ${ }^{29}$

O Direito visto nesses moldes, enquanto processo de libertação, é a grande contribuição teórica que Lyra Filho nos deixou.

Exercendo o pensamento crítico, até mesmo as vias do direito estatal podem representar uma possibilidade de ruptura com os processos de hegemonia e dominação que sujeitam os explorados e, assim, de criação de espaços voltados a uma práxis social emancipatória. Com isso, juristas marginais, como Lyra se referia a si próprio ${ }^{30}$, podem, como grande exemplo de prática do humanismo dialético, sua escola, engajar-se em usar o Direito de forma alternativa e a favor dos oprimidos.

Contudo, é importante lembrar que o próprio Lyra Filho sustenta que sua filosofia não pode se confundir com o uso alternativo do Direito. Segundo ele, é preciso enquadrar este em

\footnotetext{
${ }^{27}$ LYRA FILHO, ob.cit., 1982b. p.115.

28 Ibidem, p.109.

29 Ibidem, p.115 e 120.

30 FAORO, Raymundo. O Jurista “Marginal”. In: LYRA, Doreodó Araújo (Org.). Desordem e processo: estudos sobre o direito em homenagem a Roberto Lyra Filho na ocasião do seu $60^{\circ}$ aniversário. Porto Alegre: Sergio Antonio Fabris Editor, 1986. p.29.
} 
um “campo de visão mais larga e profunda”, categorizando-o enquanto estratégia que deve necessariamente, também, vincular-se a uma filosofia alternativa ${ }^{31}$.

Nesse ponto, Lyra Filho faz clara crítica a Barcellona, um dos principais teóricos do uso alternativo do Direito, que, segundo ele, rendeu-se a "maré direitista"32 e acabou prendendo-se nas redes de um "positivismo de esquerda" ${ }^{33}$. Pois as contradições que permitem utilizar o direito estatal de forma contra-hegemônica são apenas parte de um todo, são contradições intrassistemáticas. Assim, na totalidade social, tanto em nível infraestrutural quanto superestrutural, enraízam-se nas contradições globais que envolvem o próprio sistema normativo oficial $^{34}$. Isso implica reconhecer que a ação transformadora dentro do ordenamento jurídico estatal faz parte de uma postura estratégica, mas em si não é o bastante.

A interpretação alternativa das normas jurídicas, concretizando a possibilidade de se caminhar em uma direção emancipatória, faz parte do processo histórico, mas não o substitui.

O Direito "ampliado", ou seja, o conjunto dialeticamente integrado dos sistemas não estatais com o estatal é um espaço em que se permite lutar pela libertação do homem, ou mesmo chega a ser o "reino da libertação"35 nas palavras de Lyra Filho herdadas de Marx. 0 jurista marginal é aquele que enxerga essa totalidade do fenômeno jurídico e faz a opção por se integrar a ele na luta pelo desordenamento dos sistemas de opressão de onde poderão brotar novas conquistas aos espoliados ${ }^{36}$.

Este é o núcleo do humanismo dialético: enxergar o Direito como processo de libertação. É a grande herança de Lyra Filho para o pensamento jurídico crítico contemporâneo, em que fica claro o esforço teórico para conciliar o papel do jurista com o pensamento mais radial do materialismo dialético de Marx. Na práxis isso se reflete como o reconhecimento do papel transformador do jurista. Como defende Lyra Filho:

\footnotetext{
${ }^{31}$ LYRA FILHO, ob.cit., 1986, p.297.

32 Ibidem, p.297.

33 LYRA FILHO, Roberto. Direito do capital e direito do trabalho. Porto Alegre: Sérgio Antônio Fabris, 1982a. p.42-43.

${ }^{34}$ Ibidem, p.42-43.

${ }^{35}$ Idem, ob.cit., 1982b, p.126.

${ }^{36}$ UCHIMURA, Guilherme Cavicchioli. 0 papel do jurista marginal: ensaio sobre a perspectiva dialética do direito. Revista Crítica do Direito. São Paulo, SP, n.53, v.3, out., 2013. Disponível em:

<https://sites.google.com/a/criticadodireito.com.br/revista-critica-do-direito/todas-as-edicoes/numero3-volume-53/uchimura>. Acesso em 08 out 2013.
} 
A nossa posição de juristas não é apenas a de "conhecer e interpretar os sistemas de normas", e sim, de contribuir para que elas sejam transformadas, na direção dos movimentos jurídicos reivindicatórios de classes espoliadas e grupos oprimidos, cujos diretos ficam sacrificados setorial ou globalmente. 0 saber técnico-científico do jurista, libertado da sua função de assessorar a dominação, como no positivismo, torna-o, pelo contrário, um assessor da libertação. ${ }^{37}$

A grande questão é que, para o Direito se concretizar como um efetivo processo de libertação, como defendido, é fundamental se estabelecer um novo ensino jurídico no Brasil.

O problema, como demonstrei, está no dogmatismo que se incrustou no saber jurídico como uma grande camisa de força que o imobiliza. Romper com esse obstáculo epistemológico se impõe, portanto, como tarefa necessária para podermos ter esperança na práxis de uma teoria jurídica da libertação.

Obras como as que apresentei, infelizmente, são muito pouco conhecidas no ramo jurídico; a luta pela construção de um novo paradigma fica circunscrita a pouco estudantes e professores, cuja voz ressoa um pouco abafada em meio à grande mercantilização do ensino jurídico que, incansavelmente, apropria-se da vida acadêmica para fazer crescer sua indústria. Esses, por sua vez, muitas vezes distanciam-se dos demais em um processo de rotulação mútua, em que ambos torcem os narizes entre si e permanecem herméticos em seus mundinhos com posições sempre defensivas.

Quanto a essa condição, é preciso lembrar a distinção entre a postura sectária e a postura radical feita por Paulo Freire:

[...] a sectarização é sempre castradora, pelo fanatismo de que se nutre. A radicalização, pelo contrário, é sempre criadora, pela criticidade que a alimenta. Enquanto a sectarização é mítica, por isto alienante, a radicalização é crítica, por isto libertadora. Libertadora porque, implicando no enraizamento que os homens fazem na opção que fizeram, os engaja cada vez mais no esfôrço de transformação da realidade concreta, objetiva. [...] 0 radical comprometido com a libertação dos homens não se deixa prender em "círculos de segurança", nos quais aprisione também a realidade. Tão mais radical, quanto mais se inscreve nesta realidade para, conhecendo-a melhor, melhor poder transformá-la. Não teme enfrentar, não teme ouvir, não teme o desvelamento do mundo. Não teme o encontro com o povo. Não teme o diálogo com êle, de que resulta o crescente saber de ambos. Não se sente dono do tempo, nem dono dos homens, nem libertador dos oprimidos. Com êles se compromete, dentro do tempo, para com êles lutar. ${ }^{38}$

\footnotetext{
${ }^{37}$ LYRA FILHO, ob.cit., 1982a, p.59.

${ }^{38}$ FREIRE, Paulo. Pedagogia do oprimido. 13. ed. Rio de Janeiro: Paz e Terra, 1983. p.22 e 24.
} 
A luta pela consolidação de um novo ensino jurídico, portanto, pressupõe o enraizamento na tarefa de libertação humana daqueles que o almejam. Não há razões para estudar um Direito que apenas serve à dominação dos oprimidos; pelo contrário, há razões para transformá-lo em uma direção emancipatória e radicalizá-lo nos anseios humanos por liberdade.

Nesse sentido, engajar-se em superar a concepção do Direito enquanto instrumento de dominação, visando transformá-lo em um efetivo processo de liberação, é a tarefa do homem radical freireano, ou seja, daquele que se compromete com a libertação do homem inserindo-se na realidade para poder transformá-la.

\section{CONCLUSÃO}

A grande inquietação que deu motivação a este trabalho é a forma como o dogmatismo imobiliza o nosso ensino jurídico, como se fosse uma camisa de força positivista, castrando invencivelmente os anseios humanos por liberdade na área jurídica.

Como demonstrei, partindo dos pressupostos da epistemologia de Bachelard, o ensino jurídico, enquanto construção do saber, está sujeito a categorias que o movimentam e o realizam de forma histórica. Identifiquei, dessa forma, o dogmatismo como obstáculo epistemológico e o pensamento jurídico crítico como um conjunto de conhecimentos capaz de romper com a estagnação positivista, ou seja, como o corte epistemológico que realizaria um novo saber jurídico com a superação do modelo anterior.

Dar continuidade ao modelo tecnicista e mecanicista dos cursos de Direito é algo que só interessa aos poderosos, pois mantê-los com o caráter de meros cursos técnicos significa perpetuar o recrutamento de "soldados do capitalismo", transformando os operadores do Direito em alienados combatentes da manutenção dos privilégios de classe dos donos do capital.

O nosso papel, como defende Lyra Filho, é de não aceitar de forma alguma essa função de "assessores da dominação": libertando-nos dela, com um pensamento crítico e envolvido com a realidade social, nossa função deve ser a de assessorar a libertação humana nos movimentos dialéticos da totalidade social.

Se Boaventura está certo em dizer que estamos em um período de transição paradigmática, é fundamental que possamos des-pensar o Direito e construí-lo como base para a emersão de um paradigma emergente emancipatório. 
Deseja-se, dessa forma, que o novo ensino jurídico, a nascer da superação da crise atual, tenha, de fato, envolvimento com a realidade social em um viés emancipatório. Sendo radicais, no sentido freireano, poderemos nos enraizar na opção pela libertação humana, não aceitando mais o dogmatismo dominante no ensino jurídico, para pensarmos agora em um projeto emancipatória de saber e práxis do Direito.

A consolidação da perspectiva metadogmática do fenômeno jurídico no ensino do Direito é o primeiro passo para romper com a forma mercantil do saber jurídico, com o mecanicismo dominante na academia e com a função de servir aos poderosos que o Direito assume com a manutenção de sua ideologia positivista.

O dogmatismo, obstáculo a ser superado na realização do saber jurídico na história, deve ser combatido com a emersão do pensamento jurídico crítico como novo paradigma de ensino jurídico para que, ultrapassando a barreira positivista, o curso de Direito torne-se realmente um espaço de engajamento com a liberdade.

\section{REFERÊNCIAS}

ADORNO, Theodor W.; HORKHEIMER, Max. Dialética do esclarecimento: fragmentos filosóficos. 2. ed. Rio de Janeiro: Jorge Zahar, 1985.

BACHELARD, Gaston. A formação do espírito científico: contribuição para uma psicanálise do conhecimento. Rio de Janeiro: Contraponto, 1996.

CORREAS, Óscar. Crítica da ideologia jurídica: ensaio sócio-semiológico. Porto Alegre: Sérgio Antônio Fabris, 1995.

EHRLICH, Eügen. Fundamentos da sociologia do direito. Brasília: Universidade de Brasília, 1986.

ENGELS, Friedrich; MARX, Karl. O Manifesto Comunista. Rio de Janeiro: Nova Fronteira, 2011.

FREIRE, Paulo, Pedagogia do oprimido. 13. ed. Rio de Janeiro: Paz e Terra, 1983.

LYRA FILHO, Roberto. Direito do capital e direito do trabalho. Porto Alegre: Sérgio Antônio Fabris, 1982a.

. O que é Direito. 2. ed. São Paulo: Brasiliense, 1982b. 
- Desordem e processo: um posfácio explicativo. In: LYRA, Doreodó Araújo (Org.). Desordem e processo: estudos sobre o direito em homenagem a Roberto Lyra Filho na ocasião do seu $60^{\circ}$ aniversário. Porto Alegre: Sergio Antonio Fabris Editor, 1986.

Por que estudar direito, hoje? In: SOUSA JUNIOR, Geraldo de Sousa (Org.). 0 direito achado na rua: curso de extensão universitária à distância. Brasília: Universidade de Brasília, 1988.

MASCARO, Alysson Leandro. Filosofia do direito. São Paulo: Atlas, 2010.

MEIRELES, Cecília. Romance XXIV ou Da Bandeira da Inconfidência. In: inconfidência. 4. ed. Rio de Janeiro: Civilização Brasiliense, 1984. p.72-75 Romanceiro da

PACHUKANIS, Evgeni. A teoria geral do direito e o marxismo. Coimbra: Centelho, 1977.

PAULON, Carlos Artur. Direito alternativo do trabalho. São Paulo: LTr, 1984.

SANTOS, Boaventura de Sousa. Para um novo senso comum: a ciência e a política na transição paradigmática. v.1. A crítica da razão indolente: para um novo senso comum. 3. ed. São Paulo: Cortez, 2001.

UCHIMURA, Guilherme Cavicchioli. O papel do jurista marginal: ensaio sobre a perspectiva dialética do direito. Revista Crítica do Direito. São Paulo, SP, n.53, v.3, out., 2013. Disponível em: <https://sites.google.com/a/criticadodireito.com.br/revista-critica-do-direito/todas-asedicoes/numero-3-volume-53/uchimura>. Acesso em 08 out 2013.

WARAT, Luis Alberto. Introdução geral ao direito. v.1. Interpretação da lei: temas para uma reformulação. Porto Alegre: Sergio Antonio Fabris, 1994.

WOLKMER, Antonio Carlos. Introdução ao pensamento jurídico crítico. 8. ed. São Paulo: Saraiva, 2012.

Recebido em: 11.09.2013

Correções em: 19.11.2013

Aprovado em: 04.12.2013 